\title{
SIMULTANEOUS CONDENSATION-EVAPORATION HEAT TRANSFER ON A VERTICAL TUBE, I- EXPERIMENTAL STUDY
}

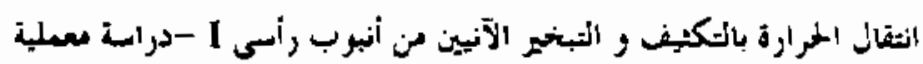

M. G. Wasel ", Hesham M. Mostafa "* and M. G. Mousa ${ }^{* *}$

"Faculty of Engineering, Mansoura Univ., Mansoura, Egypt .

" Higher Technological Institute, Tenth of Ramadan City, Egypt,

". Faculty of Education, Industrial Branch, Damietta, Mansoura Univ., Mansoura, Egypt.

خلاصة

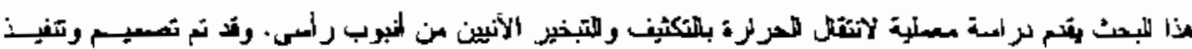

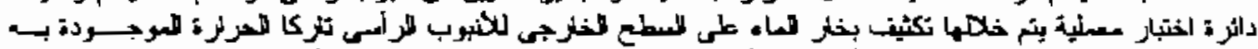

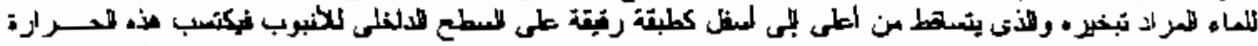

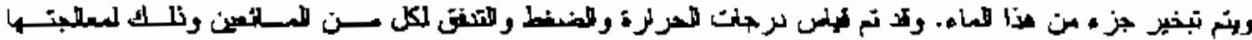

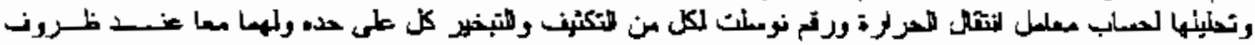

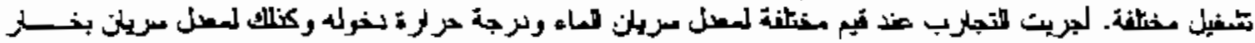

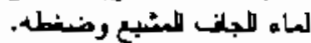

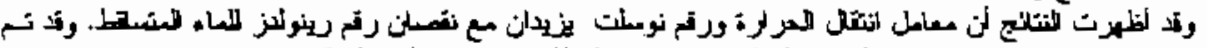

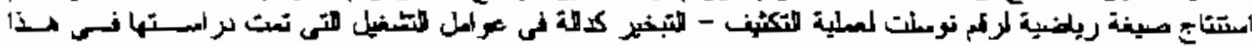

\section{ABSTRACT}

In the present work, simultaneous condensation-evaporation heat transfer in thin films on a vertical tube is, experimentally, investigated. Condensation takes place on the outer

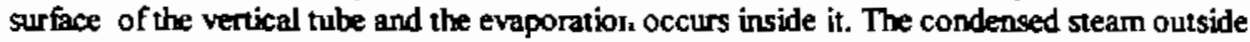
the tested tube imparts its latent beat to evaporate the thin liquid film, which flows inside the tube. Throughour this work, the range of Reynolds number for water film flow is from 50 to 800 , while that of condensate outside the tube, takes values less than 100 .

The studied operating parameters, which affect the condensation-evaporation processes are water flow rate, its degree of subcool, the flow rate of the dry salurated heating steam and its pressure. The flow rate of the falling heated water is $3-50 \mathrm{~kg} / \mathrm{hr}$ at constant pressure of $1.1 \mathrm{bar}$, while the heating steam flow rate is up $105 \mathrm{~kg} / \mathrm{hr}$ at a pressure which varies from 1.2 to 2 bar.

The results show thal, decreasing the Reyno ids number of the filling water film, up to dry out al the end of the vertical tube, causes an increase of heal transfer coefficient for different operating parameters. In addition, the Nusseit number for different values of Reynolds number are ealculated and in accordance, an empirical correlation for the condensation - evaporation Nusselt number as a function of the studied operating parameters is proposed.

Key words: Condensation - Evaporation - Verical tube

\section{NOMENCLATURE}

$\begin{array}{lll}A & \text { Surface area } & \mathrm{m}^{2} \\ c_{p} & \text { Specific heat at constant pressure } & \mathrm{J} / \mathrm{kg} \mathrm{K} \\ d_{m} & \text { Mean diameter of the tube } & \mathrm{m} \\ h & \text { Heat transfer coefficient } & \mathrm{W} / \mathrm{m}^{2} \cdot \mathrm{K} \\ h_{f, s} & \text { Latent heat } & \mathrm{J} / \mathrm{kg}\end{array}$




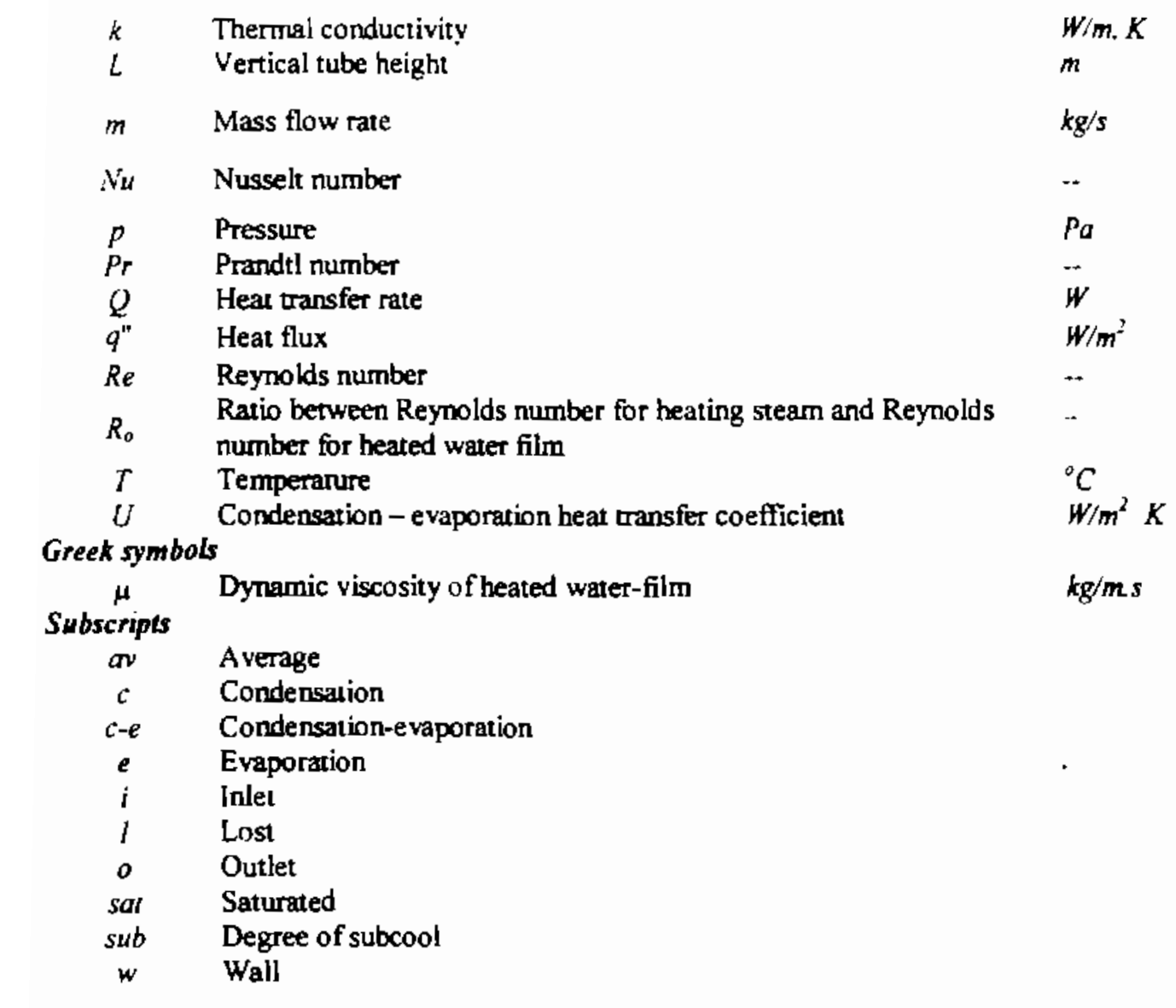

\section{1NTRODUCTION}

The phenomenon of film condensation-evaporation occurs in many practical situations and is of great interest in several technical areas specially hear exchange devices such as desalination units, heat exchangers, refrigeration units, peuroleum refinery and food industries ...etc. Yan et al [1-2] studied, experimentally and numerically, the evaporative cooling of liquid film in vertical channel. A numerical analysis was carried out to sudy the detailed heat transfer characteristics of a falling liquid film by solving the goveming equations for the liquid film and induced gas flow together. The measured data were in good agreement with the numerical prediction.

Condensation over surfaces was studied in considerable detail [3-5]. Legay et al [3] studied. experimentally and numerically, heat transfer in an incompressible xoundary layer associated with condensation over a vertical flat plate. Condensation effects may be used in various problems, to improve the efficiency of some heat exchangers. Experimental and numerical calculations were performed for laminar boundary layer. Experimental study of the imterface between a condensing vapor region and an interfacing fluid was carried out by Jaluria [4]. The study considered the steady state and transiem behavior of the interface. Forced convective film condensation inside vertical tube was performed by Chen et al [5]. 
Simultaneous condensation-evaporation process. at different values of operating conditions. was analyzed by Mahgoub er al [6]. The effects of heat flux. falling mass flow rate and pressure ratio on local and average heat transfer coefficients are investigated, experimentally and theoretically, for horizontal tube. Fmpirical correlation relating the dimensionless groups. which govern the evaporation and condensation in laminar flow region. was proposed. Moalem et al [7] and Sideman et al [8] studied overall heat transfer coefficient in horizontal evaporator-condenser tube in case of low heat flux and laminar flow regime.

Seeking for good understanding of simultaneous evaporation-condensation process, more studies are needed to be carried out. In the present work. heat transfer by simultaneous condensarion- evaporation process on vertical tube wall is. experimentally, studied.

\section{EXPERIMENTAL TEST-RIG}

To study the simultaneous condensation-evaporation process on a vertical tube, a testrig is designed and constructed, such that the condensation takes place at the outer surface of the tested tube; while the evaporation occurs at its inner surface. The layout of the test-rig is illustrated in figure ( $1-\mathrm{a})$. It consists of two loops, the first one is associated with the heating steam, while the second loop is for the heated inner water-film.

Considering the heating stean loop, the generated steam is produced using a boiler of $9 \mathrm{~kW}$ rated power (2) and of $0.4-\mathrm{m}$ diameter and $0.6-\mathrm{m}$ height. To insure that, the heating steam enters the test section (1) dry and saturated, it passes through a warer trap (3). The heating steam impars its latent heat to the heated inner water-film, as it flows along the outer surface of the tested tube and it, consequently, becomes liquid water at the bottom of the test section. This condensed steam is directed to the boiler and there it is re-boiled.

On the other hand, considering the loop of the heated water-film, the water is led; from a constant water-level tank (S), to a stainless steel tested tube of $19-\mathrm{mm}$ diameter, thickness $1 \mathrm{~mm}$ and $1-\mathrm{m}$ heighr. As the heated water flows along the inner surface of the tested tube. some of the water is evaporated. This evapcrated water is directed to condenser (4), while the rest of the heated water is directed to the boiler (2).

Figure (1-b) shows the details of the test section. The heated water enters the test tube (1) through the adjustable position (guide) plate (2). This guide plate is mounted at the inlet of the test tube, to control the mass flow rate of heated water. Another job of it is to insure that the water flows along the tube as a thin liquid film adjacent to the inner surface of the tested tube (1). Heating steam enters the test section through the port (8) and leaves it, a condensate, through the port (4). To insure that, the heating steam condenses, only, at the ourer surface of the tested tube (I), an insulating steam jacker (7) is used. The stearn used in this jacket is of the same condition of the heating steam of the tested tube ( inlet from por (II) and exit from port (I2)).

Pressure and temperacure of both heating steam and heated water are measured at their corresponding inlet cross-sections using Bourdon tube dial gauge and $\mathrm{K}$ type thermocouples; respectively. The temperature of condensate (of the heating steam) is, also, measured at its exit (at the bottom of the test section). The flow rate of the heating steam and the evaporated vapor, as liquid water, is measured by calibrated tank. The temperature of the outer surface of the tested tube is measured at three positions along the tube length. 


\section{DATA REDUCTION}

The measured temperature, pressure and mass flow rate of both heating steam and heared water-film are used to calculate eondensation, evaporation and condensationevaporation heat transfer coefficients and, in lurm, the corresponding Nusselt number. The imparted heat from the heating steam can be estimaled according to the following relation as:

$$
Q_{c}=m_{\varepsilon} \cdot\left[h_{f g, c}+c_{p}\left(T_{s a t, c}-T_{c, o}\right)\right]
$$

Where $m_{c}, h_{f, c}, c_{p}, T_{s o L c}$ and $T_{c, 0}$ are mass flow rate of heating steam, latert heat of condensation, specific heat at constant pressure, sanuration temperarure of heating steam and the temperature of the leaving condensed steam; respectively. The amount of heat transfierred to the evaporated water film is:

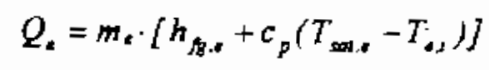

Where $m_{*}, h_{f s,}, c_{p}, T_{s a, e}$ and $T_{e, r}$ are mass flow rate of evaporated vapor, latent heat of evaporation, specific heat at constant pressure, saturation temperature of evaporated vapor and the temperature of the water-film at the inlet cross-section; respectively. The heat transferred to the un-evaporated part of the water-film is estimated as the difference between the heat transferred from the heating stearn; equation (1) and that transferred to the evaporated part of water film; equation (2). This quantity of heat can be estimated according to the following equation:

$$
Q_{1}=Q_{\mathrm{c}}-Q_{\text {s }}
$$

$Q_{i}$ may be considered as the lost heat through the evaporation process. One can neglect the heat loss compared to the heat of heating steam. The heat flux can defined according to the following relation as:

$$
q^{\prime \prime}=Q_{c} / A
$$

Where $A$ is the hear transfer surface area, which is defined as; $A=\pi d_{m} L$. The mean diameter of the tested tube and the tube height are denoted by $d_{m}$ and $L$; respectively.

Condensation, evaporation and condensation-evaporation heat transfer coefficients are defined according to the following equation:

$$
h_{c}=q^{\prime \prime} /(\Delta T)_{c}, h_{v}=q^{\prime \prime} /(\Delta T)_{\text {\& \& }} \quad U=q^{\prime \prime} /(\Delta T)_{c-s}
$$

Where $h_{c}, h_{e}$ and $U$ are heat transfer coefficient of condensation side, evaporation side and condensation - evaporation; respectively. $\left(\Delta T_{c \cdot e}\left(=T_{\text {sal, }}-T_{\text {sat. }}\right)\right.$; is the total temperature difference, while $(\Delta T)_{e}\left(=T_{s o t, c}-T_{v, c}\right)$. denotes the temperature difference in condensation side and $(\Delta T)_{e}$ is the temperature difference in the evaporation side $\left[(\Delta T)_{e}=T_{x, t}-T_{\text {sal,e }}\right]$. The wall temperalure at the condensation and evaporation sides are denoted by $T_{w, c}$ and $T_{w, e}$; respectively. In accordance, one can define the corresponding Nusselt number for the condensasion, evaporation and condensatinn-evaporarion as:

$$
N u_{c}=h_{s} \cdot d_{m} / k, N u_{q}=h_{q} \cdot d_{m} / k \& \quad N u_{c-s}=U \cdot d_{m} / k
$$


Where $\mathrm{k}$ is the thermal conductivity of the corresponding film and at its average remperature. Through out the present work. the Reynolds number has the following definition:

$$
R e=m_{t} / \pi d \mu
$$

Where $\mu$ is the dynamic viscosity of the heated water-film.

The uncertainties are determined for both measured and calculared quantities. The uncertainty of ternperanure difference is estimated as about $0.142{ }^{\circ} \mathrm{C}$, while the largest calculated uncertainties in the Reynolds number was found to be about $3.1 \%$ and that of Nusselt number is about $12.6 \%$.

\section{RESULTS AND DISCUSSIONS}

Figure (2) shows the relation between the heat flux and the saruration temperature difference, between the condensation and evaporation sides for all studied cases, at different operating conditions. Throughout the present study, the degree of subcool for the falling water film is in the range $2-30^{\circ} \mathrm{C}$. During the experiments, the condensate leaves the tube, almost, as saturated warer.

The evaporated vapor mass flow rate versus mass flow rate of heating steam, for the whole range of the studied operating conditions, is presented in figure (3). It is generally observed that, the evaporated vapor flow raxe is less than the heating steam mass flow rate by a slight value. However, for some operating conditions the falling water-film, of higher values of degree of subcool, consumes a considerable amount of heat, in such a case, a decrease of the amount of evaporated vapor is expected.

The Nusselt number and heat transfer coefficients of condensation and evaporation against Reynolds number are shown in figure (4) at the heating steam pressure of 1.6 bar and heat flux of $22 \mathrm{~kW} / \mathrm{m}^{2}$. It is observed that, condensation heat transfer coefficient is greater than evaporation heat transfer coefficient for all carried out experiments. In addition, both condensation and evaporation heat transfer coefficients increase with decreasing Reynolds number. Nusset number has the same behavior like that of hear transfer coefficient for both condensation and evaporation.

The Nusselt number $\left(\mathrm{Nu}_{c \cdot \varepsilon}\right)$ and heat transfer coefficient (U) of simultaneous condensation-evaporation process versus Reynolds number of the heated water-film (Re) are illustraxed in figure (5). It is observed that for all values of Reynolds number, that the Nusselt number takes higher values for higher heat flux. At certain heat flux, Nusselt number increases with decreasing Reynolds number. This increase in Nusselt number (and heat transfer coefficient) can be explained as, the decrease in Reynolds number causes a decrease in the water-film thickness and, in turn, the thermal resistance decreases.

The experimental results in the considered range of Reynolds number (50-800) shows that, the average Nusselt number may be related to Reynolds number by the following proposed correlation:

$$
N u_{c-。}=16.94 \operatorname{Re}^{03} R_{o}^{1.6} \operatorname{Pr}^{2.8} \quad \text { for } \quad 1.5<\operatorname{Pr}<2.25
$$

Where $R_{o}\left(\mathrm{R}_{\mathrm{o}}=\mathrm{Re}_{\mathrm{c}} / \mathrm{Re}_{\mathrm{e}}\right)$ is the ratio between Reynolds number of heating steam, and that of the heared water-film. 
The effect of saturation temperature difference $\left(\Delta T_{i-e}\right)$ on the condensation evaporation Nusseit number is shown in figure (6). The increase of this temperature difference causes an expected decrease in the heat transfer coefficient and consequently in Nusselt number for the same value of heat flux. As it is clear from the same figure, decreasing degree of subcool increases Nusselt number and heat transfer coefficient, for the same value of Reynolds number. Referring to the definition of Reynolds number [equation (7)], one can see that, this increase of both Nusselt number and heat transfer coefficiem may be due to the decrease of the water-film thickness.

A comparison between the present results and that of other previous works in [7] is shown in figure (7). The present proposed correlation as represems fairly good, the actual present results is shown in figure. Athough the values of the case vertical tube are higher than that of [7], the obtained Nusselt number of condensation- evaporation for horizontal tubc after [7] has the same trend as that of present results. There is no data available in both condensations -evaporation in vertical tube but the previous work has the condensation only or evaporation only in vertical tube.

\section{CONCLUS1ONS}

In the present work, simultaneous condensation-evaporation heat transfer on a vertical iubc was, experimentally, studied at different operating parameters. Condensation takes place on the outer surface of the verical tube and evaporation on it inside surface. The studied operating parameters are flow rate and degree of subcool of heated water-film, and flow rate of dry saturated heating steam and its pressure.

The results show that, condensation-evaporation Nusselt number increases with increasing heat flux. In addrion, Nusselt number of condensation and evaporation, and Nusselt number for simultaneous condensation-evaporation are increased with decreasing Reynolds number. A correlation for Nusseh number as a function of the flow parameters is proposed.

\section{REFERENCES}

[1] Yan, W.M. and Lin, T.F. (1991) "Evaporative Cooling of Liquid Film Through Interfacial Heat and Mass Transfer in a Vertical Channel -I Experimental Study" Int. J. Heat Mass Transfer, Vol. 34, No. 4, pp. $1105-1111$.

[2] Yan, W.M. aod Lin, T.F. (1991) "Evaporaive Cooling of Liquid Film Through Interfacial Heat and Mass Transfer in a Vertical Channei -II Numerical Study" Int. J. Heat Mass Transfer, Vol. 34, No. 4, pp. 1113-1124.

[3] Legay, F., and Pruaet-Foch (1986) "Heal transfer with condensation in laminar boundary layers along a flat plate" Int. J. Heat Mass Transfer, Vol. 29, No. 1, pp. 95-105.

[4] Jaluria ,Y (1979) "An experimental study of the interface of a condensing vapor region" Int. J. Heat Mass Transfer, Vol. 22, pp. 865-873.

[5] Chen, S.L., and Ke, M.T, (1993) "Forced convective film condensation inside vertical tube" Int. J. Murtiphase Flow, Vol. 19, No. 6, pp. 1045-1060

[6] Mabgoub, M. M., Wasel, M. G., and Mousa, M,G., (2000) " Theoretic al Analysis of Evaporator- Condenser Horizontal Tube" Al-Azhar Engineering sixth International Conference, 1-4 September, pp.258-268.

[7] Moalem, D. and Sideman, S.(1976) "Theoretical analysis of horizontal condenser evaporator tube". Int. J. Heat Mass Transfer, Vol.19, pp.259- 270.

[8] Sideman, S., Moalem, D., and Semiat, R. (1976) "Theorerical analysis of horizontal condenser-evaporator conduits of various cross section" Desalination. 17, pp.167-192. 


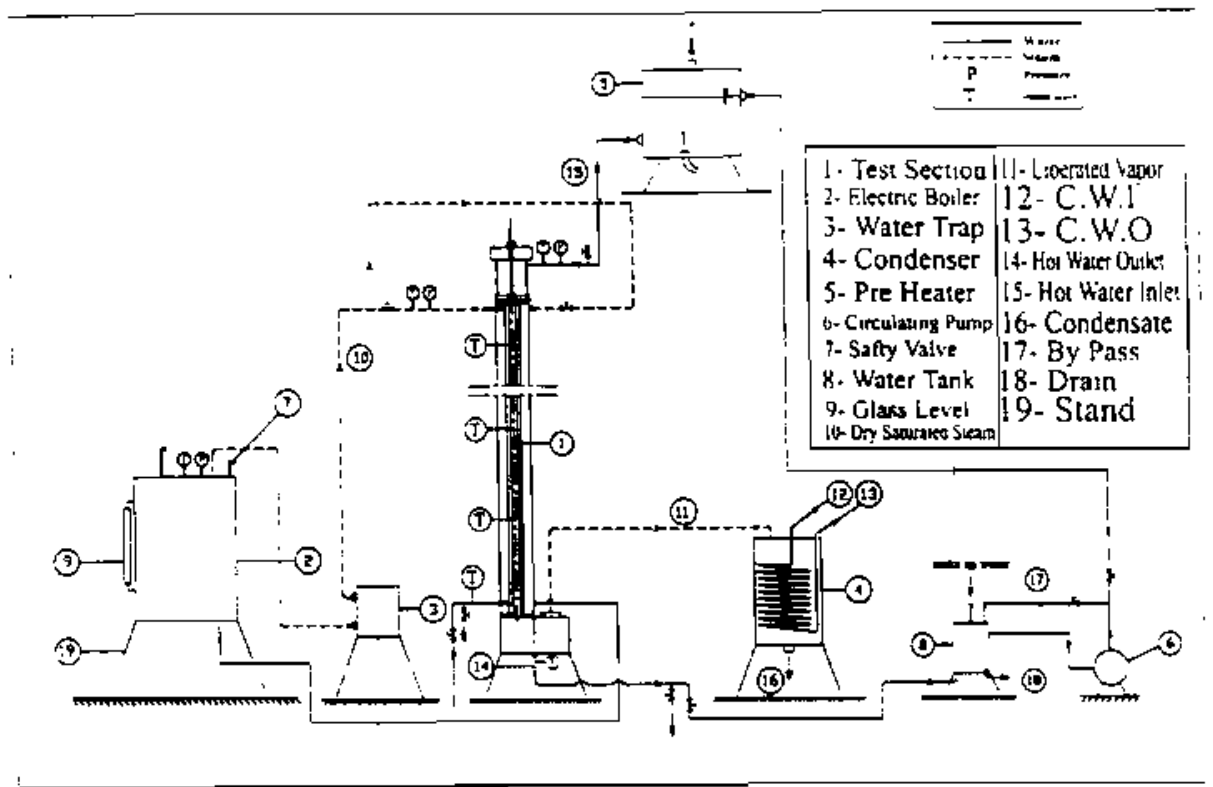

Fig.(1.a) Schematic layout of test -rig
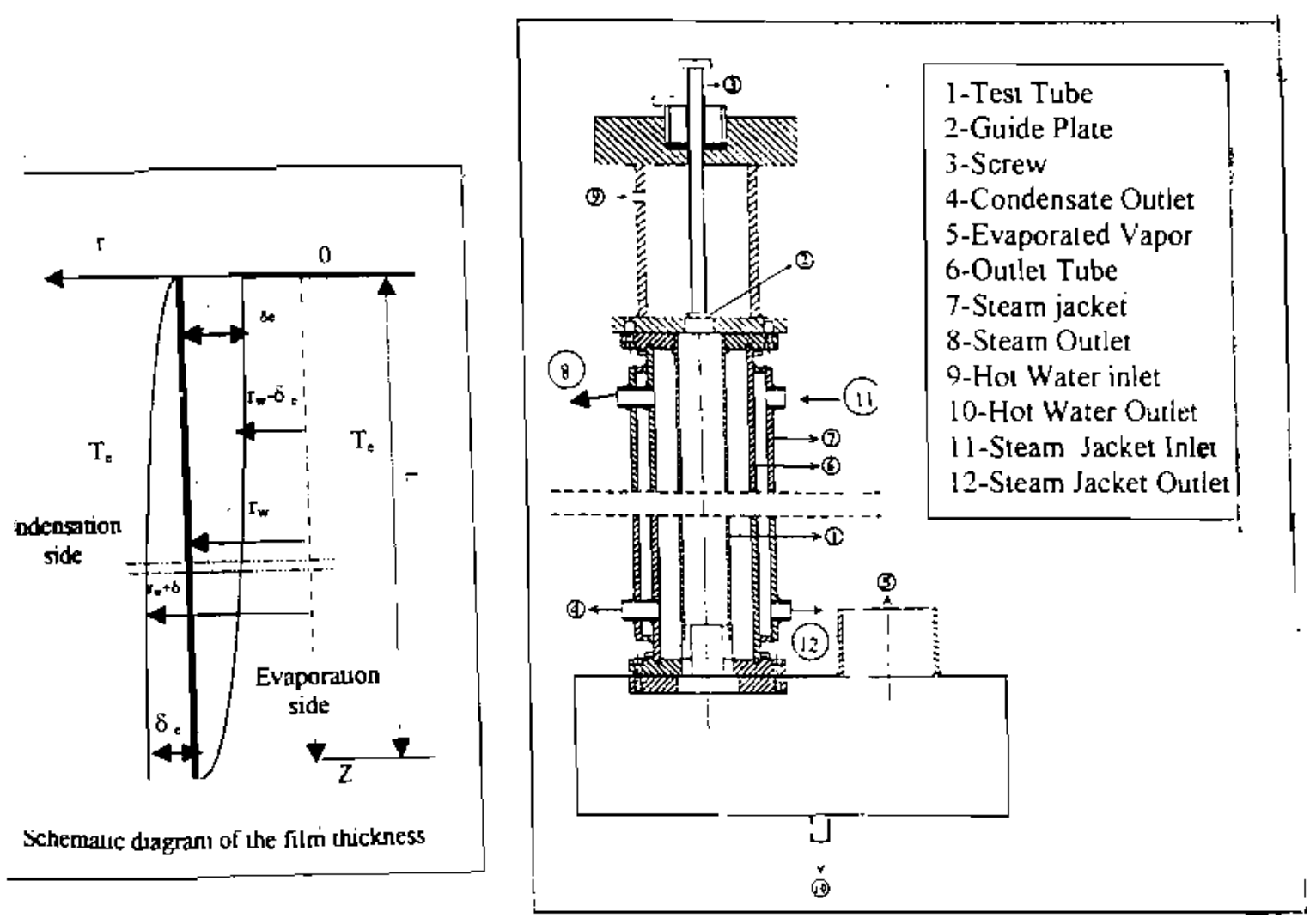

Fig (1.b) Test section 
M. 99

M. G. Wasel, Hesham M. Mostafa and M.G. Mousa

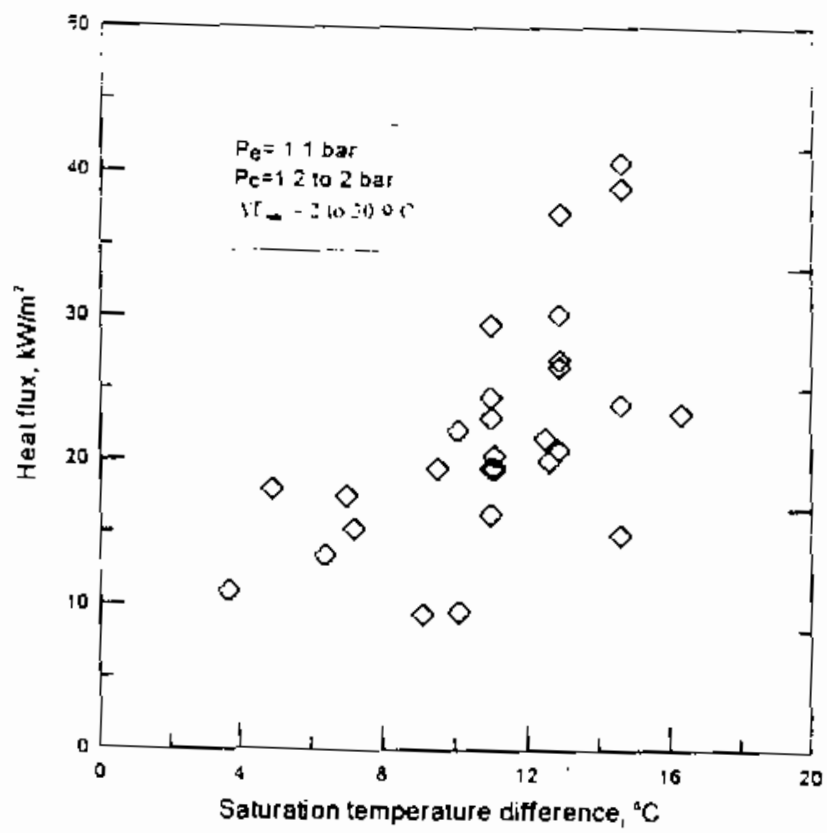

Fig. (2) Heat flux versue saturation temperature difference bermeen candensation and evaporatton sldes for the whole range of the studted operating conditions

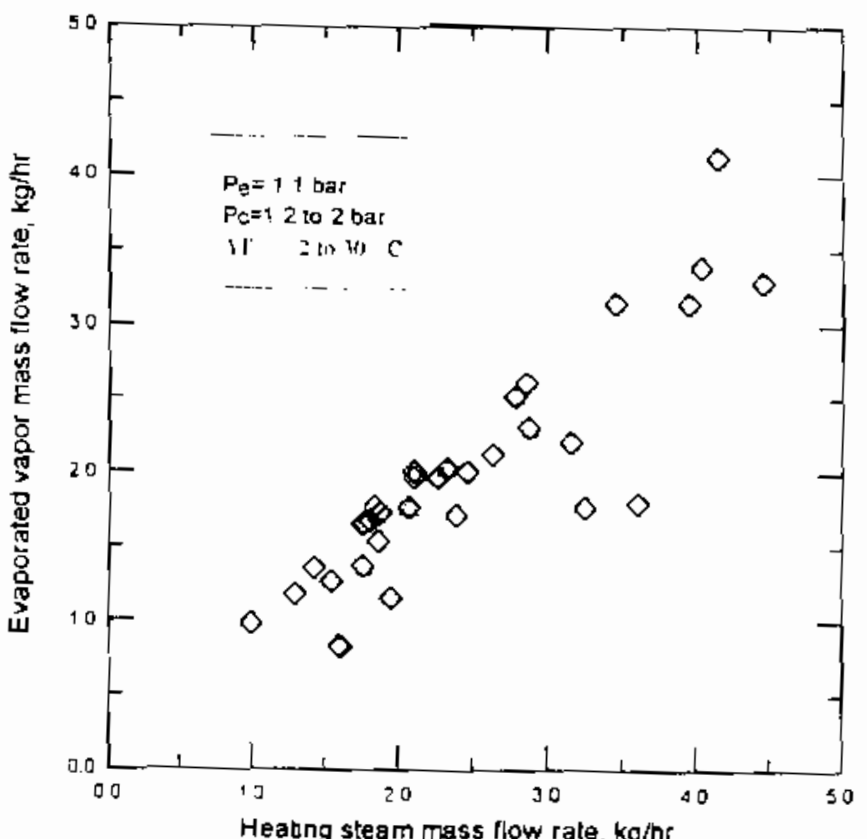

Flo. (3) Evaporated mass flow rato versus heating steam mass flow rate for the whole range of the studled operating candtions 


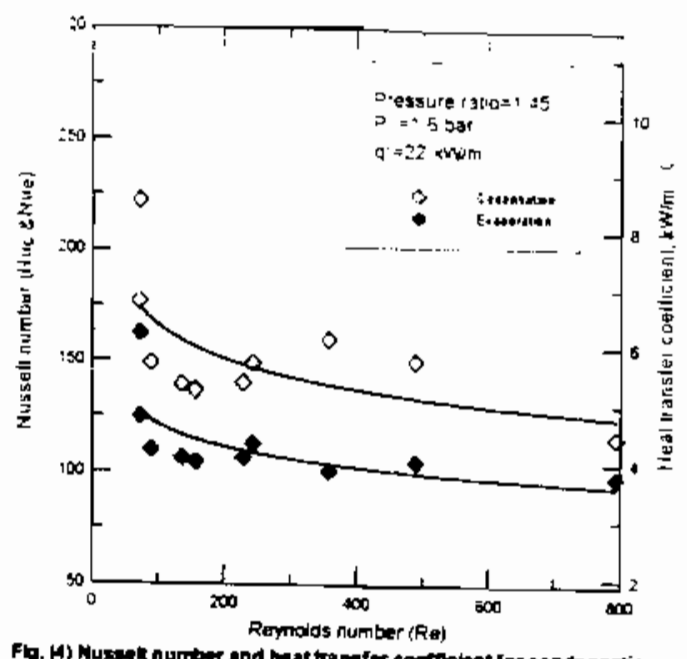

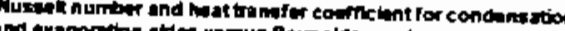

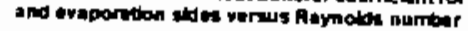

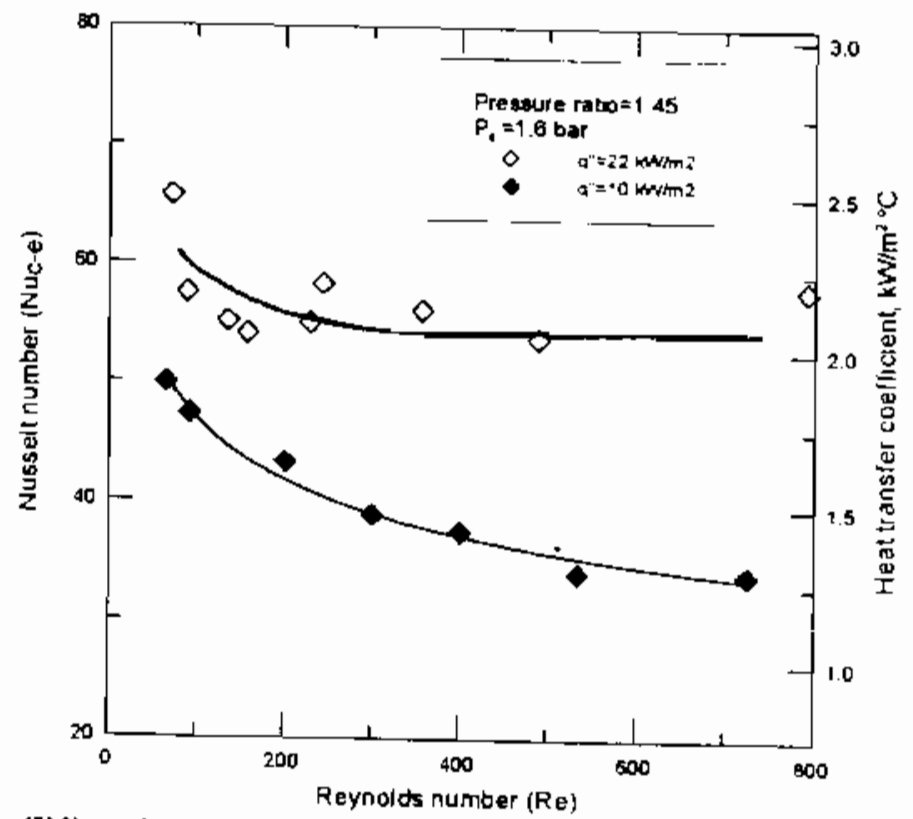

Fig. (5) Nusselt number and heat transfer coefflelent versus Reynolds number for simulaneous condensaton-evaporation process 
M. 101 M. G. Wasel, Hesham M. Mostafa and M.G. Mousa

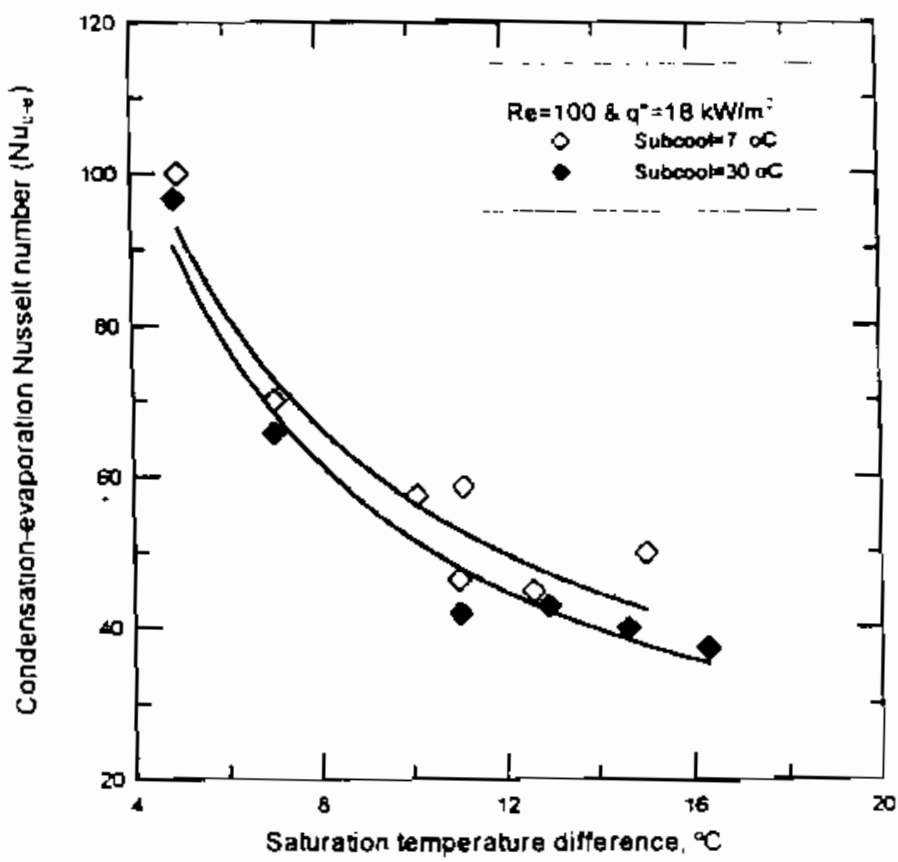

Fig. (6) Nuss en number versus saturation temperature difforence for different degree of subcool

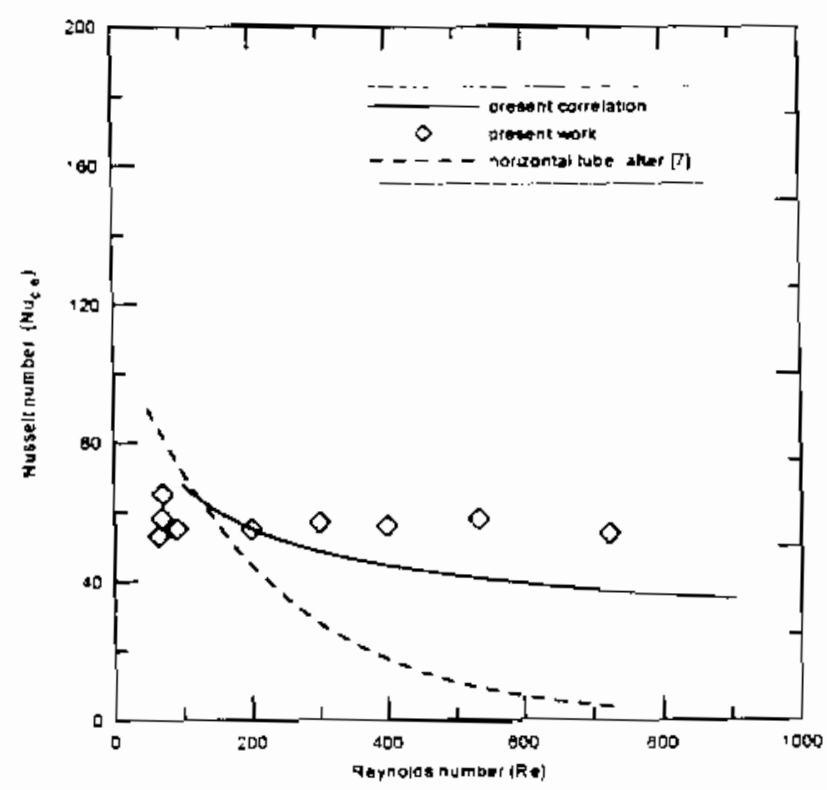

Fig. (7) Comparison between the present work and previous work 